\title{
THE EFFECT OF DIGITALIS ON THE CARDIAC OUT-PUT OF DOGS AND ITS BEARING ON THE ACTION OF THE DRUG IN HEART DISEASE
}

\author{
BY TINSLEY RANDOLPH HARRISON AND BERNARD W. LEONARD \\ (From the Department of Medicine, Vanderbill University)
}

(Received for publication May 10, 1926)

\section{INTRODUCTION}

The mode of action of digitalis has been a subject of discussion and experimentation since Witherings' classical observations which introduced the drug into medicine. In spite of extensive investigation, the essential problem, the effect of the drug on the out-put of the heart of patients suffering from cardiac insufficiency, remains insolved. Our knowledge along this line has been summarized by Robinson (1) as follows:

"The relation of the effect of digitalis on ventricular contractions to its beneficial influence in heart disease has been discussed but this problem has not as yet been definitely solved. . . . . In spite of the uncertainty which actually exists digitalis has been generally considered for many years as a so-called 'heart tonic' and its beneficial effect has been considered as mainly due to an increased out-put of the heart by its action on the muscle itself."

The literature on digitalis has been carefully reviewed by Robinson and, more recently, by Cushny (2). In this paper only those studies which bear directly on the effect of the drug on cardiac out-put will be mentioned.

Gottlieb and Magnus (3) and Magnus and Sowton (4) found that the work per beat of the perfused mammalian heart is increased by digitalis, the work per minute being either increased or decreased according to the degree of slowing. Cushny (5) using the cardiometer found an increase of 20 to 30 per cent in minute out-put in the intact heart, while in the denervated or atropinized heart the effect was 
variable, there being usually no significant change in out-put (6). Schmoll (7) holds that digitalis acts by affecting the tonicity rather than the contractility of the cardiac muscle, while others, notably Gottlieb (8), Schmiedeberg (9) and Cushny (10) believe that the essential action lies in augmented contractility. Cohn (11) points out that these discrepancies in results may be ascribed to variations in dosage and method, and emphasizes the fact that experimental doses have usually been in excess of therapeutic doses. In 1915 Cohn stated that an increase in the out-put of the heart resulting from the action of digitalis in therapeutic doses had not been demonstrated either clinically or experimentally. In $1920 \mathrm{Cohn}$ and Levy (12) studied the effect of intravenous injections of digitalis and $\mathrm{g}$-strophanthin in dogs and cats, by means of volume curves. The results were somewhat variable, the output being usually but not always increased in dogs, and unchanged or diminished in most of the cats. Strong and Gordon (13) showed that strophanthin given intravenously decreases the size of the heart of normal rabbits and of rabbits with experimental myocarditis. Recently Levy (14) has demonstrated a decrease in the size of the heart as determined by the $\mathrm{x}$-ray after digitalization in pneumonia, while Cohn and Stewart (15) have demonstrated an increased excursion of the ventricles in man as judged by "moving" orthodiagrams. Vagt (16) calculated the cardiac out-put after digitalis by studying the arm volume and the blood pressure. He concluded that the drug caused a slight increase in the stroke out-put and a slight decrease in pulse rate. Kaufman (17) using another indirect method concluded that the out-put per beat was increased by 10 per cent and the out-put per minute decreased about 10 per cent. All the above methods except the cardiometric are indirect and subject to many errors.

The only direct measurements of the effect of digitalis on the cardiac out-put of man are those of Eppinger, von Papp and Schwarz (18). They used a modification of the Plesch method and during an extensive study of "cardiac asthma" they record two observations in which the effect of digitalis on the out-put of the heart in patients with heart disease was determined. In one instance they found a definite diminution in the cardiac out-put per minute after the patients had received full therapeutic doses of the drug. In the other case diminution 
occurred, but its relation to the action of the drug is uncertain. These observations are the only direct measurements, so far as we are aware of the effect of digitalis on the out-put of the heart.

The effect of digitalis on the regularly beating heart of patients with cardiac insufficiency has been much discussed. The beneficial influence of the drug when auricular fibrillation is not present and when the cardiac rate is not definitely altered is naturally referred to its effect on the heart muscle. Under these circumstances it has been generally inferred that digitalis improves the efficiency of the heart by increasing its out-put, and that this effect results from the direct action of the drug on the heart muscle. However there is not agreement that digitals is usually beneficial under these conditions.

The foregoing review may be briefly summarized as follows.

1. A general impression prevails among clinicians that digitalis increases the out-put of the heart.

2. The majority of pharmacologists support this view, their evidence being based on experiments with the perfused heart and on observations on anaesthetized animals after various operative procedures. In much of the experimental work digitalis has been used in amounts larger than are used therapeutically.

3. The effect of digitalis on the minute cardiac out-put of man has been measured directly in two instances, and in both a significant decrease was observed.

Further studies of the cardiac out-put in man are desirable. The existing methods applicable to human subjects require intelligent cooperation, and they are at best tedious and subject to error. For this reason our present study has been carried out on dogs. It is hoped that the effect of digitalis on the cardiac out-put of patients with heart disease may be studied later.

\section{METHOD}

The experiments were carried out on dogs in a quiet state. To avoid the exertion of struggling the animals were usually given morphine 0.012 gram per kilo of body weight. Seven experiments were done however on trained dogs that did not require morphine. One animal was used as a control, morphine alone being given. The animals were placed on their backs on an animal board. 
Thirty to ninety minutes after receiving morphine a sample of venous blood was drawn from the right ventricle and a sample of arterial blood was taken from the left ventricle or from the femoral artery. When the animal struggled the samples were discarded. The oxygen content of the arterial and venous bloods was determined by means of the Van Slyke-Neill (19) constant volume apparatus. Check analyses were made, the same sample of blood being used in most instances, although in several of the experiments on the smaller dogs two arterial and two venous samples were analysed in order to avoid the possibility of "mixed" blood.

Immediately after the blood samples were drawn the oxygen consumption was determined with the Benedict spirometer. The Roth graphic recording device was used. Duplicate five- or ten-minute periods were taken.

In earlier experiments tracheotomy was done. In later work and in the observations on trained animals a specially constructed rubber bladder was blown air tight around a piece of dental rubber dam which fitted the dog's nose. (We are very much indebted to our colleague, Dr. Alfred Blalock, for demonstrating this procedure to us and for the use of his apparatus.) This procedure renders tracheotomy unnecessary and is simpler and easier than using plasticine and paraffined plaster of paris mask. In the course of numerous experiments we have not once been troubled with leaks, which occasionally occur when the mask is used. Blalock's method also makes it possible for one observer to carry out the entire blood flow determination, as the rubber bladder does not have to be held over the animal's head by a second person.

The cardiac out-put per minute was calculated according to the Fick formula:

$\frac{\text { Cubic centimeters of } \mathrm{O}_{2} \text { consumed per minute }}{\text { Amount of } \mathrm{O}_{2} \text { taken up by } 1 \mathrm{cc} \text {. of blood in }}$ equals $\begin{aligned} & \text { cubic centimeters of blood passing } \\ & \text { through the lungs per minute }\end{aligned}$ passing through the lungs

Electrocardiograms were taken either immediately before or immediately after the determination of oxygen consumption. In some of the longer experiments electrocardiograms were also made in the intervals between the blood flow determinations.

After one-in some instances two-control determinations of cardiac 
out-put, the animals were given digifolin (Ciba) intramuscularly. The amount of the drug used varied in different experiments, according to the weight of the animal and according to whether the therapeutic or toxic effect was desired. The initial dose was never more than 0.5 cc. per kilo (17 minims per 5 pounds) which represents approximately the therapeutic dose of digifolin for dogs according to Pardee (20) and which corresponds to 3 grams of the powdered leaf for a 150-pound man.

In some of the experiments this full therapeutic amount was given at the first dose. However in most instances this was given in two or three doses over a period of eight to twelve hours. In earlier experiments the effect of additional or toxic doses was also studied although in the later experiments interest centered entirely on the results obtained from the full therapeutic dose. In order to increase the margin of safety for the trained animals slightly smaller doses were used for them.

Three to five hours after the first dose of the drug the cardiac output was again determined, another electrocardiogram taken and a second dose of the drug given.

The amount used and the exact procedure varied somewhat in the different animals as shown in the tables.

Two experiments were carried out on trained animals with an increased metabolic rate, which had been previously produced by feeding thyroid gland. One experiment was peformed on a dog with elevated metabolic rate after frequent bleedings. These three animals had an increased cardiac out-put at the start of the experiment and offered an opportunity to study the effiect of digitalis on the hyperdynamic heart. (The effects of bleeding and of changes in metabolic rate on cardiac out-put have been studied by Blalock and Harrison and will be published at a later date.)

In two experiments on narcotized animals the usual procedure was carried out and subsequently the vagi were cut and the cardiac out-put again measured. In four experiments on trained unnarcotized animals atropine was given after digitalization and the effect on cardiac out-put determined.

In one experiment the rate of recovery from digitalis was studied by measuring the cardiac out-put every twenty-four to forty-eight hours until an approach to the normal level was found. 
In all nineteen experiments were carried out and eighty-four determinations of cardiac out-put were made.

\section{RESULTS}

The effect of morphine alone is shown in table 1. A diminution of 8 per cent of the original cardiac out-put occurred over a period of twenty-two hours. This is within the possible limits of error of the method, although the average variation in check experiments is considerably less than this.

TABLE 1

Control experiment showing effects of morphine alone

\begin{tabular}{|c|c|c|c|c|c|c|c|}
\hline $\begin{array}{c}\text { Dog Bs } \\
7.2 \mathrm{kggm}\end{array}$ & $\mid \begin{array}{c}\text { Oxygen } \\
\text { con- } \\
\text { sump- } \\
\text { tion }\end{array}$ & $\left|\begin{array}{c}\text { Arterial } \\
\text { oxygen } \\
\text { content }\end{array}\right|$ & $\left|\begin{array}{l}\text { Venous } \\
\text { oxygen } \\
\text { content }\end{array}\right|$ & $\begin{array}{c}\text { Coeffi- } \\
\text { ceient } \\
\text { of utili- } \\
\text { zation }\end{array}$ & $\left|\begin{array}{c}\text { Cardiac } \\
\text { output } \\
\text { per } \\
\text { minute }\end{array}\right|$ & $\begin{array}{c}\text { Pulse } \\
\text { rate }\end{array}$ & Data of experiments \\
\hline & $\begin{array}{l}c c \text { per } \\
\text { minute }\end{array}$ & $\begin{array}{c}\text { vol. } \\
\text { per cent }\end{array}$ & $\begin{array}{l}\text { sol. } \\
\text { per cent }\end{array}$ & & cc. & & \\
\hline I & 58.8 & 17.07 & 10.72 & 6.35 & 926 & 92 & $\begin{array}{l}\text { January } 21,2: 10 \text { p.m. control elec- } \\
\text { trocardiogram. } 2: 35 \text {, morphine } \\
0.06 \text { gram. } 3: 45, \text { tracheotomy. } \\
\text { 4:30, first determination }\end{array}$ \\
\hline II & 60.6 & 17.74 & 11.18 & 6.56 & 924 & 90 & 8:00 p.m., second determination \\
\hline III & 62.5 & 16.77 & 9.49 & 7.28 & 859 & 139 & 11:25 p.m., third determination \\
\hline IV & 67.7 & 16.91 & 9.27 & 7.64 & 886 & 250 & $\begin{array}{l}\text { January 22, 12:15 p.m., fourth } \\
\text { determination }\end{array}$ \\
\hline
\end{tabular}

"Determination," as used in this and the following tables, denotes the approximate time at which bloods were drawn, oxygen consumptions determined and electrocardiograms taken.

In Table 2 the effect of digitalis on the morphinized animals is shown.

In Table 3 the effect of the drug on trained unnarcotized animals is recorded.

Analysis of these tables brings out the following points:

\section{Pulse rate}

No constant changes from therapeutic doses of digitalis were noted in the morphinized dogs. Initial slowing was found in three instances, but was slight with one exception, which is mentioned in detail in the discussion of changes in cardiac mechanism. Therapeutic doses 
TINSLEY R. HARRISON AND BERNARD W. LEONARD

TABLE 2

Showing the effect of digitalis on dogs narcotized with morphine

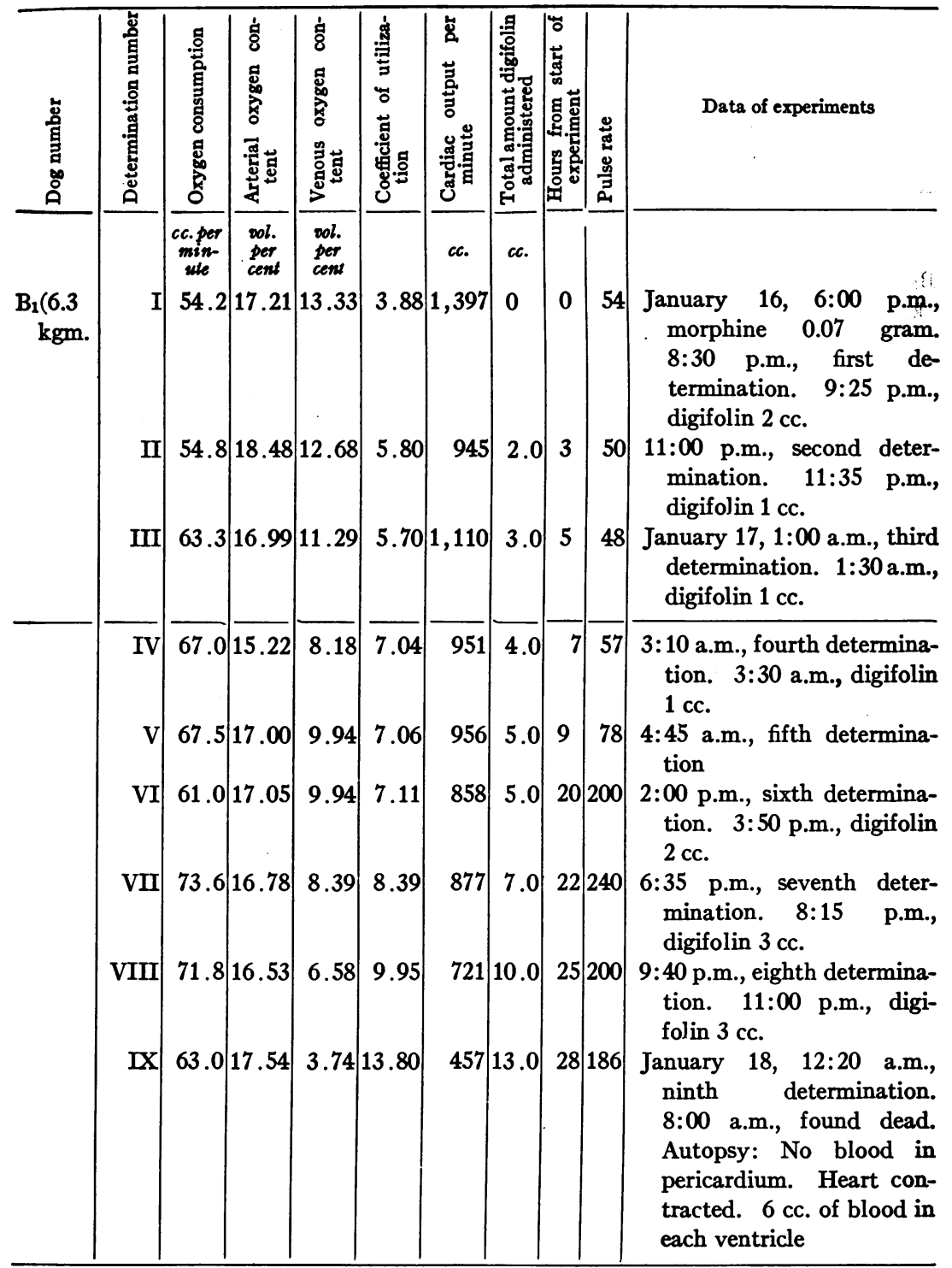




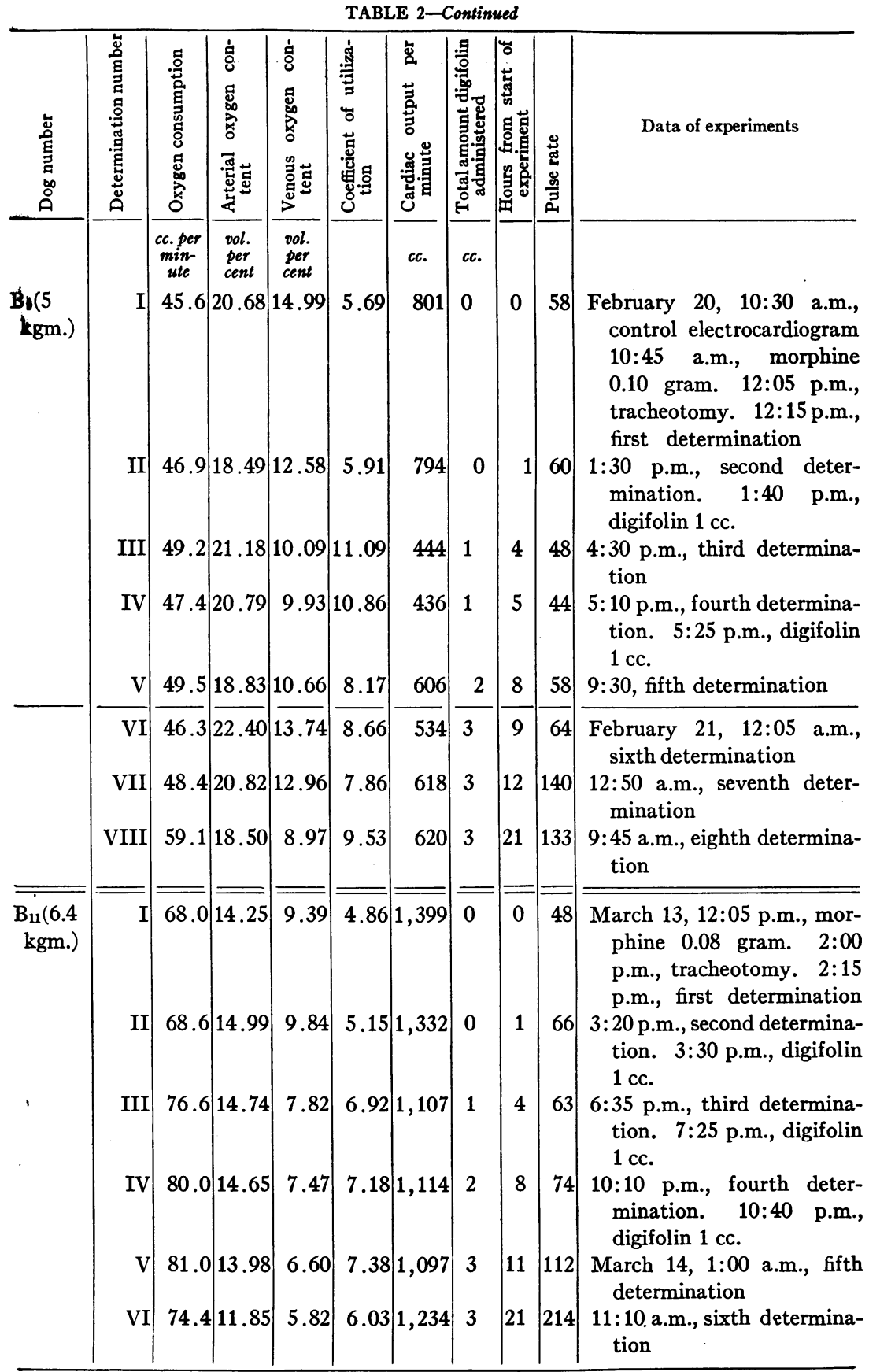


TINSLEY R. HARRISON AND BERNARD W. LEONARD

TABLE 2-Continued

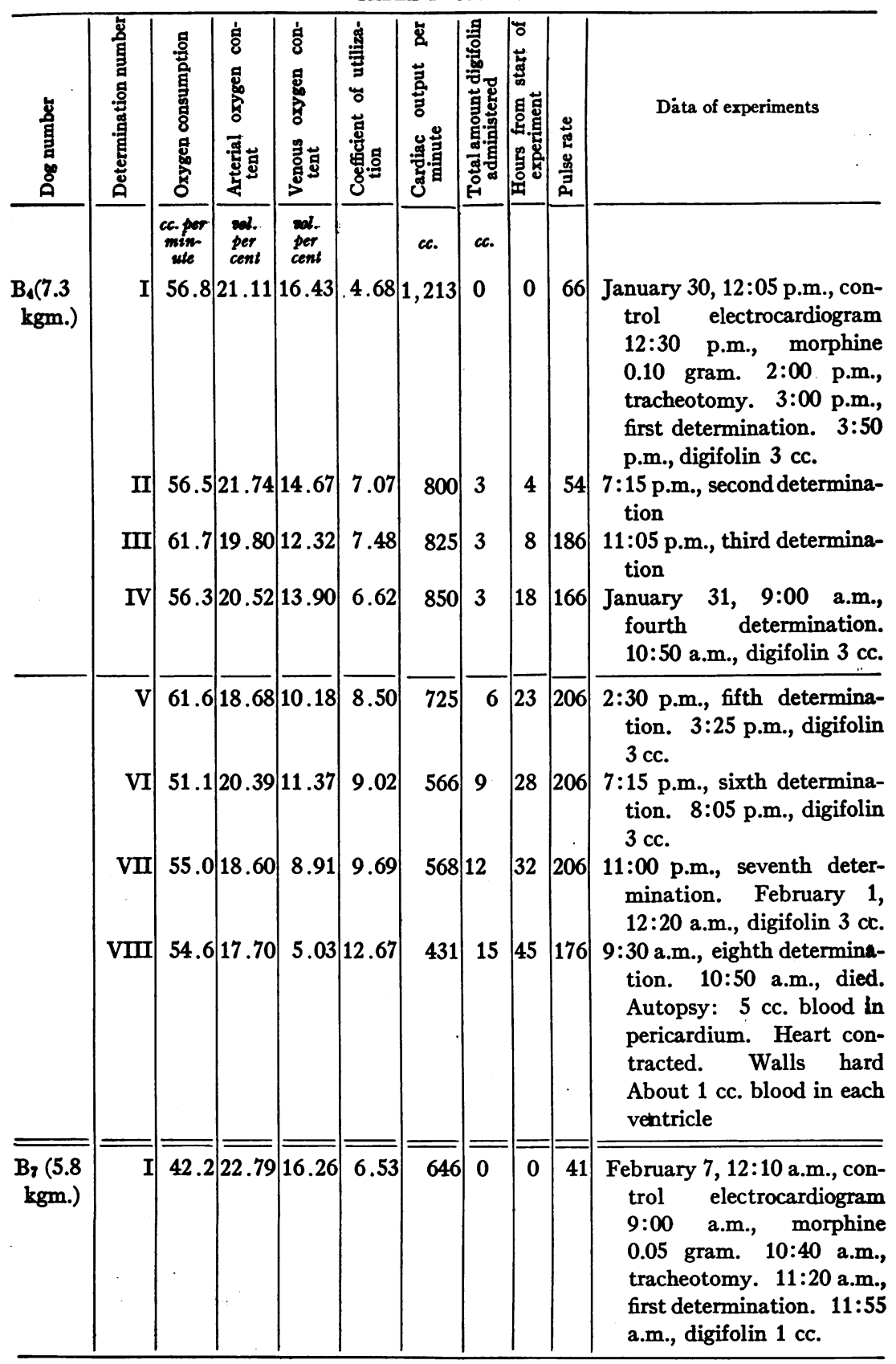


TABLE 2-Continued

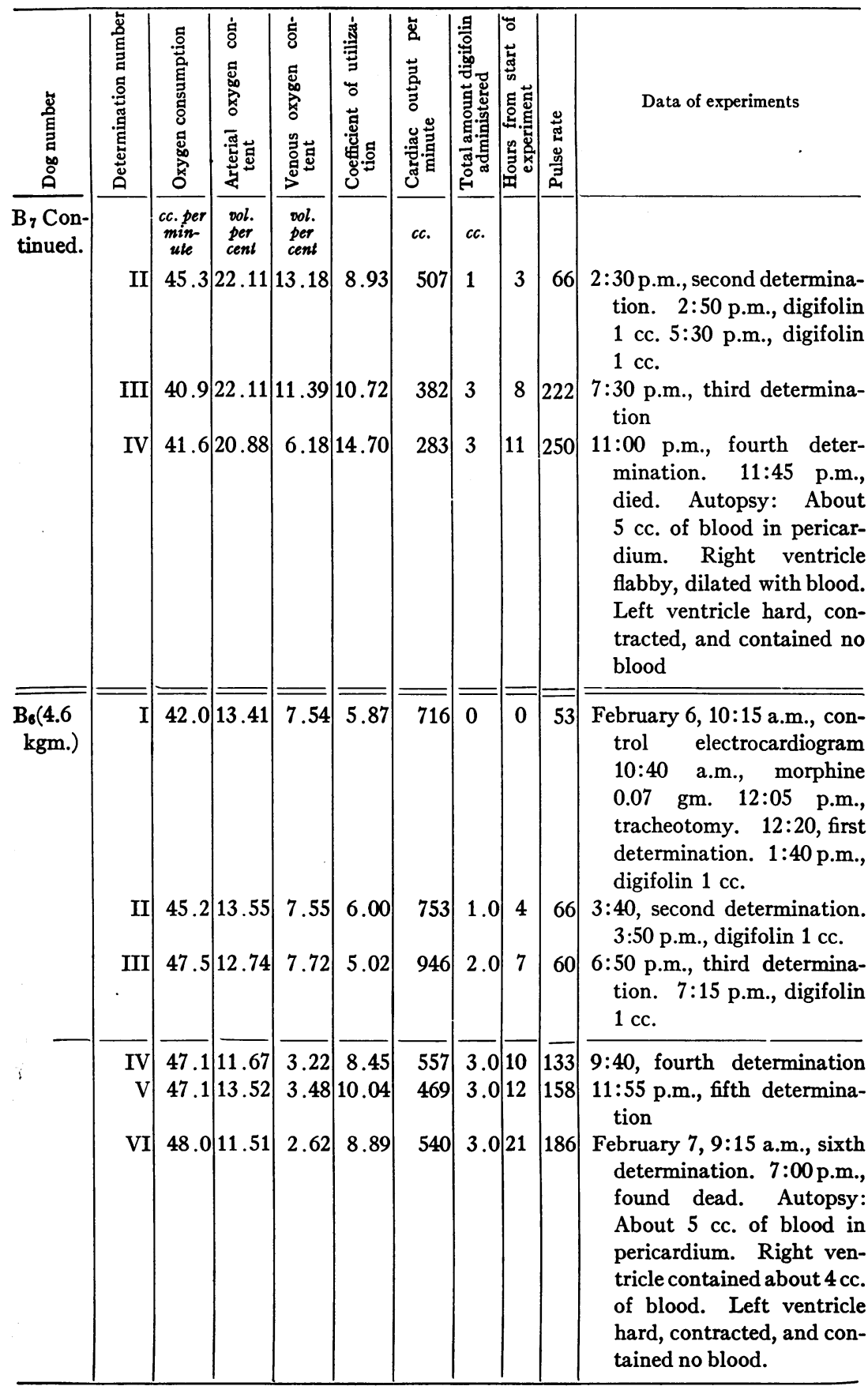


TABLE 2-Concluded

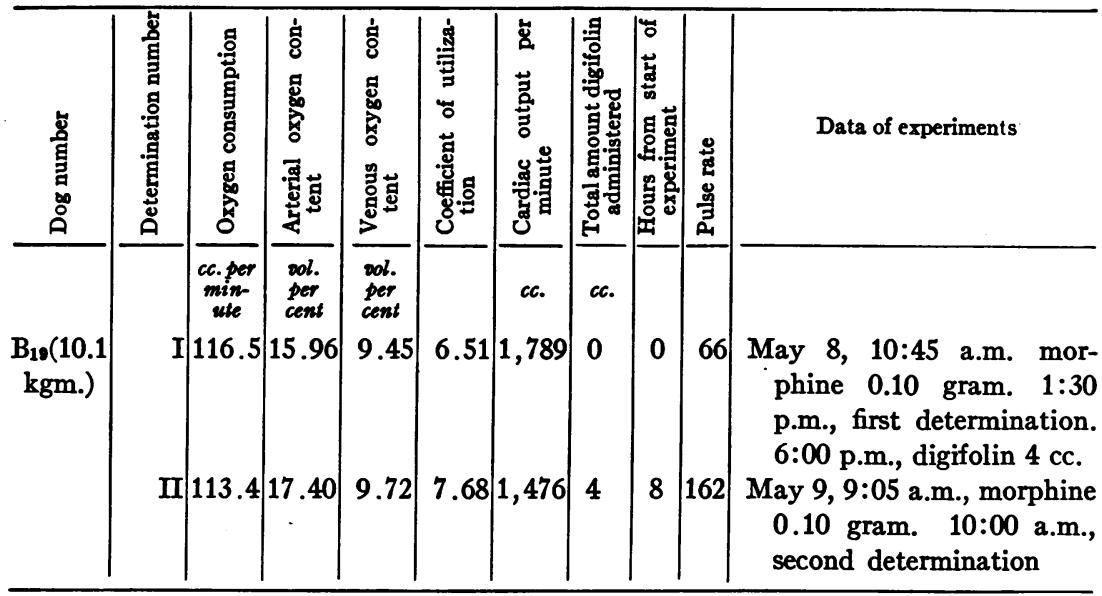

Note: The line drawn through each experiment denotes the division between toxic and therapeutic doses.

produced an increase in pulse rate in six experiments. The changes in pulse rate in the morphinized animals are felt to be of less significance than the changes in the trained dogs, for morphine causes a marked slowing of the pulse, and this effect wears off before the narcotic effect is lost. In the seven experiments on trained dogs the pulse rate was diminished 18 to 24 beats per minute in four instances and was increased by 11,22 , and 100 beats per minute in the other instances, the dose of the drug not exceeding the "full therapeutic" dose in any instance.

Toxic doses caused a marked increase in pulse rate in every instance.

\section{Oxygen consumption}

This remained fairly constant in most instances. In the morphinized dogs a slight increase was noted several times as the experiment progressed. We believe this can be explained by slight restlessness as the effect of the morphine diminished. The trained dogs usually showed a decrease in oxygen consumption after digitalization. The cause of this is not clear. In seven experiments on trained dogs the oxygen consumption increased in two and decreased in five, whereas the cardiac out-put decreased in every instance. The maximum 
TABLE 3

Showing effect of digitalis on trained unnarcotized dogs

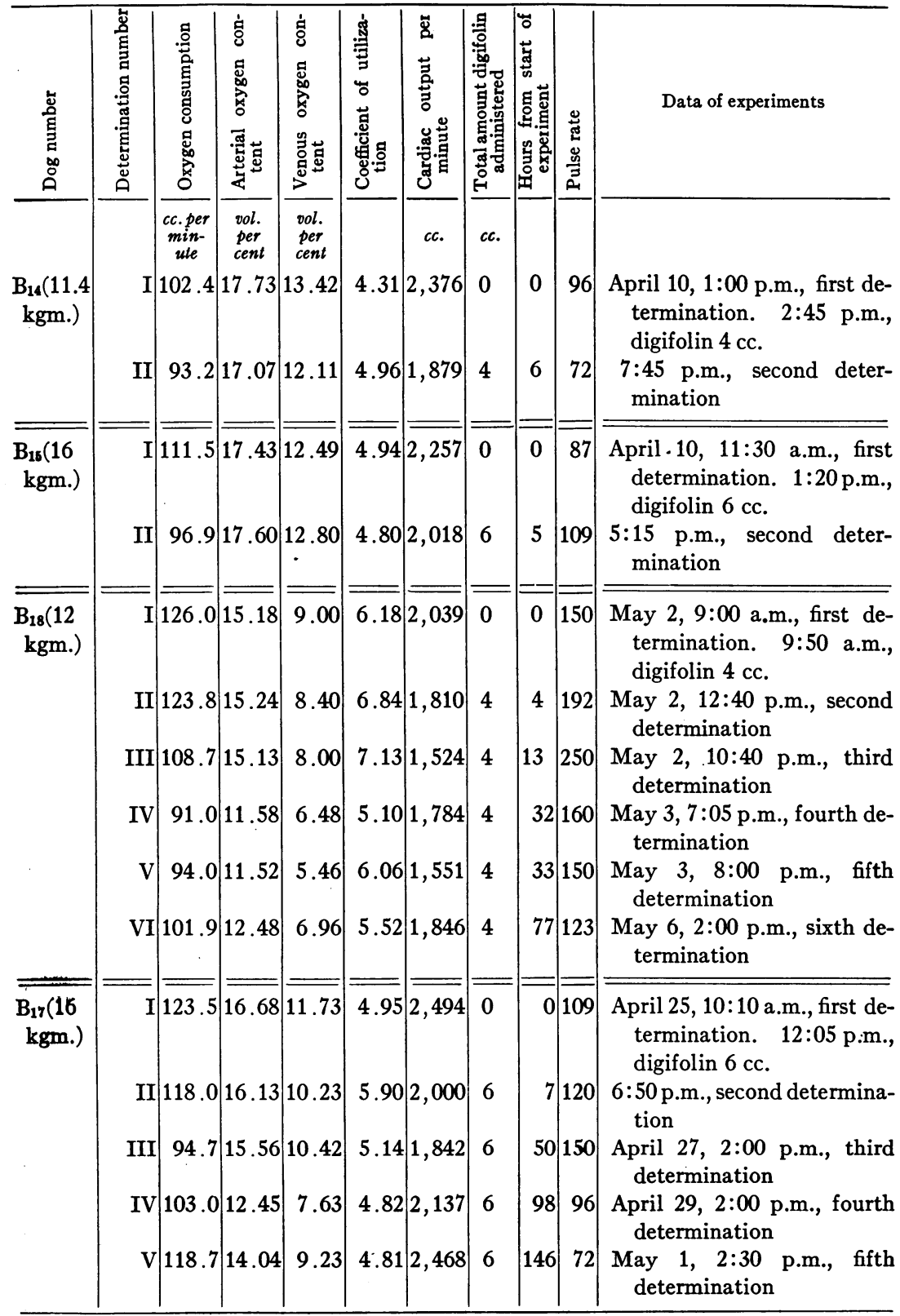

Note: The doses of digifolin were all "sub-therapeutic," i.e., less than 0.5 cc. per kilogram. 
decrease was 19.5 per cent in oxygen consumption and 36.2 per cent in cardiac out-put. The average change in this group was -6.1 per cent in oxygen consumption and -20.7 per cent in cardiac out-put. Changes found in cardiac out-put cannot, therefore, be attributed to variations in metabolic rate.

\section{The arterial and venous oxygen contents}

Variations of one to two volumes per cent in arterial oxygen content were frequently encountered, and in some of the longer experiments a drop of as much as three or four volumes per cent was found. In several instances the arterial oxygen content increased, then decreased and again increased. Such changes were probably dependent on body readjustments to bleeding, with water coming into the blood stream from the tissues or red blood cells passing from the spleen into the general circulation (Barcroft (21)). The changes noted in cardiac out-put in these experiments cannot be attributed to bleeding, because Blalock and Harrison, in some unpublished observations, have found that bleeding of comparable degree produces no appreciable immediate effect on the out-put of the heart, whereas the effect on the cardiac out-put that occurs later is an increase rather than a decrease. The venous oxygen content diminished after digitalis, and this drop was greater than the arterial decline.

The coefficient of utilization-arterio-venous difference-decreased in three instances, remained unchanged (change of less than $0.2 \mathrm{vol}$. per cent) in 9 instances, and increased in 45 instances in a total of 57 determinations after digitalis.

\section{The cardiac out-put}

As this is the essential phase of the problem the results, which are shown in tables 2 and 3, and figures 1,2, 3, and 4, will be analyzed in some detail. In a total of 57 determinations after digitalis the minute out-put of the heart was increased in three instances and decreased in 54 instances. The increases were 3, 6 and 32 per cent. The first two figures are within the limits of error of our method. The increase of 32 per cent was obtained in one determination during an experiment in which the other determinations yielded the usual decreased values for cardiac out-put. We are inclined to think that this single ex- 
ception to our general findings was probably the result of obtaining "mixed" blood, which would lower the arterio-venous difference and give a false high value for the cardiac out-put. However, as this is only an assumption and cannot be proven, this finding is included in our tables and figures.

The relationship between the degree of decrease in cardiac out-put and the amount of digitalis administered. On the basis of Pardee's (20)

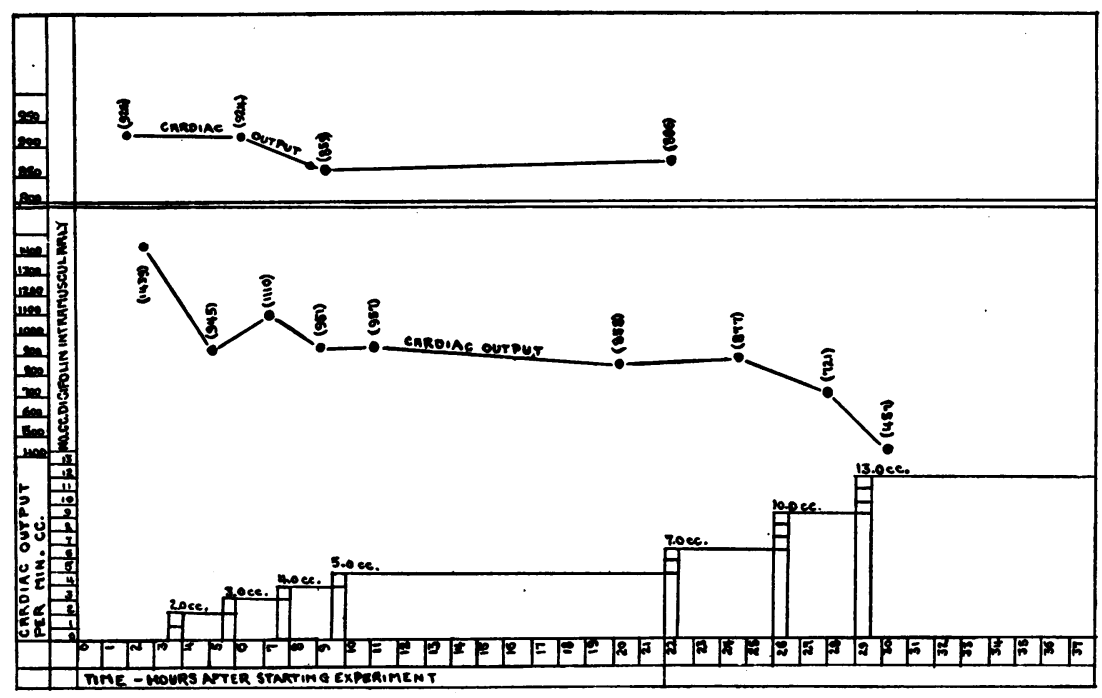

Fig. 1. The Effect of Morphine and of Digitalis on Cardiac Out-put

The experiment shown above the double line represents a control experiment carried out on an animal which received morphine but no digitalis (table 1, $\left.\operatorname{dog} \mathrm{B}_{3}\right)$.

The experiment shown below the double line represents one control determination after morphine, but before digitalis, and eight determinations after digitalis had been given (table $2, \operatorname{dog} B_{1}$ ).

In the control experiment the maximum variation in four measurements of out-put over a period of 22 hours was $67 \mathrm{cc}$. (8 per cent). In the digitalis experiment the minimum decline in cardiac out-put was $329 \mathrm{cc}$. (23 per cent). The degree of decrease in cardiac out-put is shown to be rather loosely correlated with the amount of digitalis given.

observations we have assumed that $0.5 \mathrm{cc}$. of digifolin per kilogram of body weight of dogs is equivalent to the full therapeutic dose for man. We have divided the determinations after digitalis into four groups 
according to the amount of digitalis received. The maximum, minimum and average changes in cardiac out-put in each group are shown in table 7 .

The values are expressed in terms of the percentage change from the control determinations. As can be seen from the figures in the last line the degree of decrease in cardiac out-put is correlated with the amount of the drug given. This is shown by figure 3 .

One rather striking point is the fact that the drug in smaller doses (column I, table 7) had a very definite effect, whereas doses up to one

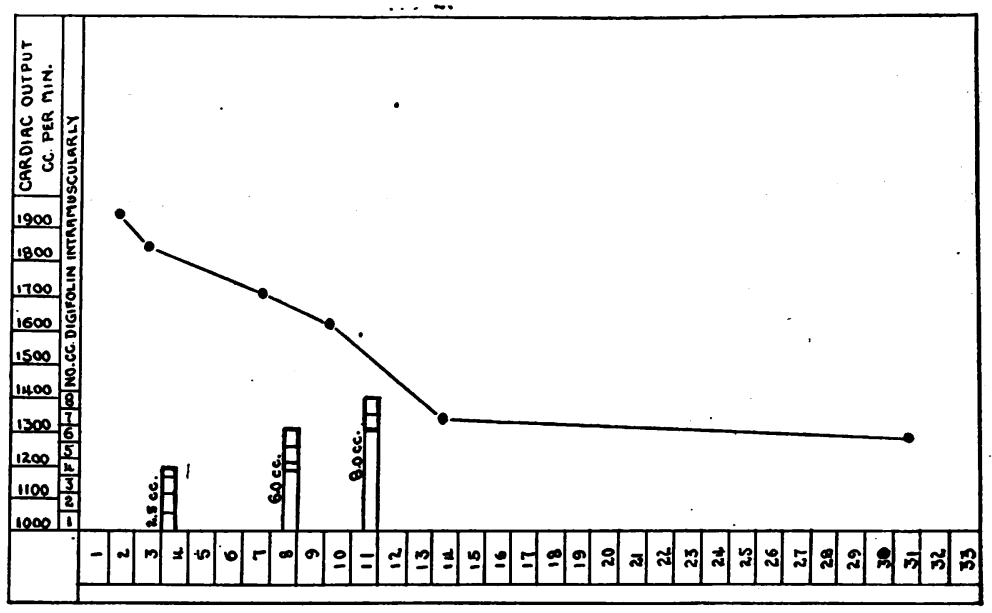

Fig. 2. The Effect of Digitalis in a Dog with Auricular Fibrilation

The effect of increasing doses of digitalis is shown in a dog with auricular fibrillation (table 5, Dog $B_{13}$ ). The steady decline in cardiac out-put as the amount of the drug was increased is noteworthy.

and one-half times the "full therapeutic" dose did not have much more effect than did the therapeutic and sub-therapeutic doses. Figure 3 also illustrates the marked variations in the individual animals. In every instance, with the three exceptions mentioned above, the action of the drug was similar qualitatively but the quantitative effect was very variable.

The relationship between the time the drug was given and the onset and duration of the maximum effect has not been carefully studied in this work. Such observations as have been made indicate that digi- 
folin given intramuscularly causes a reduction in cardiac out-put in two to three hours or less time, but this reduction does not reach its maximum until about six hours after administration. The maximum effect after a "full therapeutic" dose lasts for three to four days; the cardiac out-put then increases and reaches the original level in six to

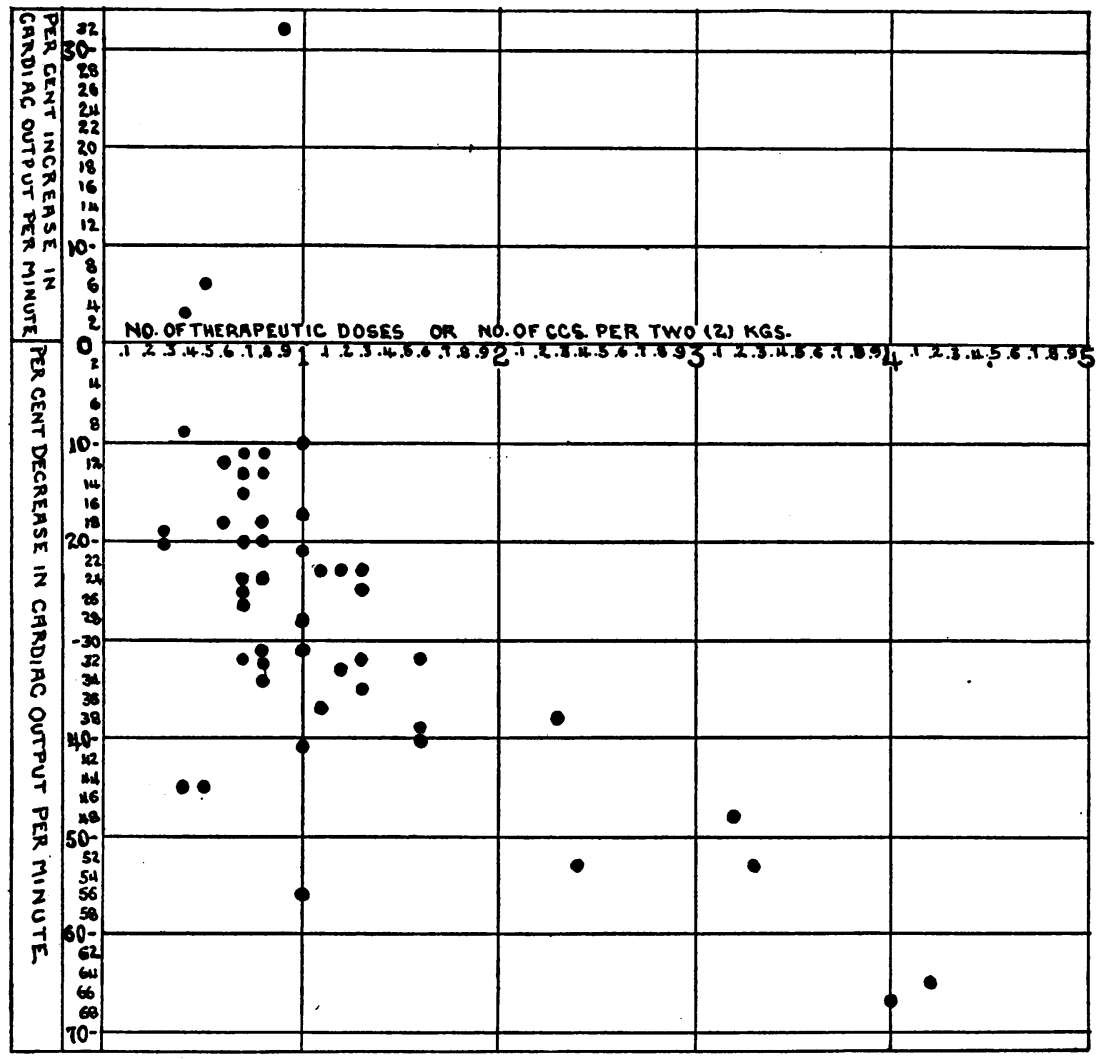

Fig. 3. The Effect of Digitalis on Cardiac Out-put

Each dot represents a determination after digitalis. The percentage change in cardiac out-put is plotted against the dose of the drug. In only three instances was an increased cardiac out-put found. The " $O$ " horizontal line represents the control out-puts. The first vertical line represents the "full therapeutic" dose. Despite the marked individual variations the average degree of decrease in cardiac out-put is shown to be almost a linear function of the amount of the drug administered. 
eight days. In figure 4 an experiment (table $3, \operatorname{dog} B_{17}$ ) is shown in which the "full therapeutic" dose was given and the "recovery" followed.

The out-put per beat of the heart is a very variable factor, as has been demonstrated by practically all observers who have studied this problem in man and as has recently been demonstrated for trained unnarcotized dogs by Marshall (22) and for morphinized dogs by Harrison, Wilson and Blalock (23). Henderson, who for a long time supported the idea of a uniform stroke volume has recently come to believe that his earlier ideas were erroneous (24). There is now

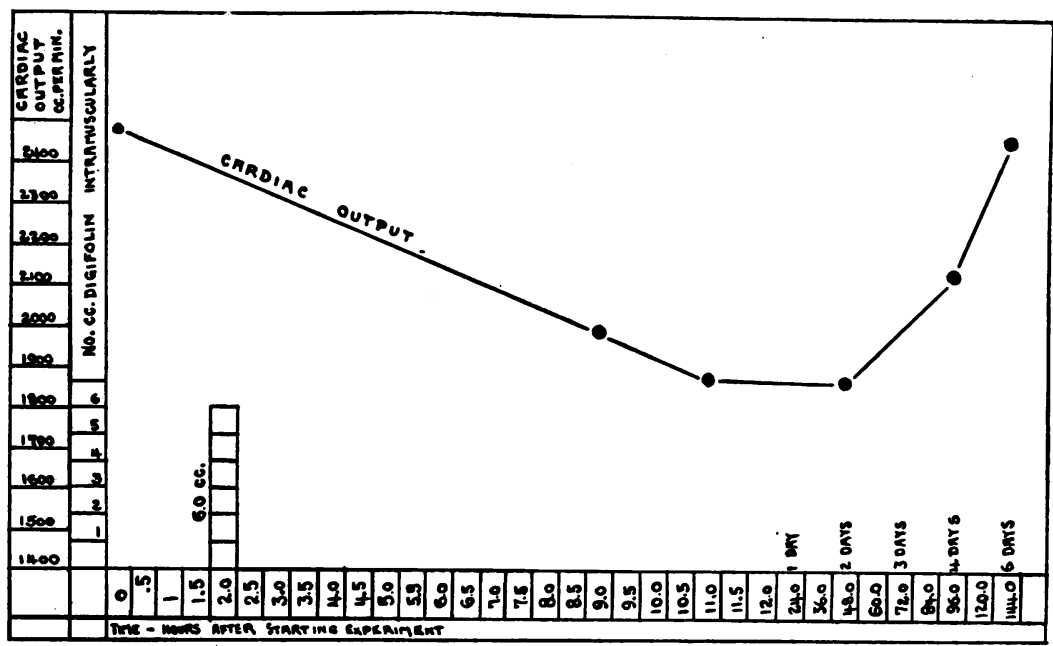

Fig. 4. The Thme of OnSEt and Duration of the Effect of Digitalis on Cardiac OUtput

The "recovery" was studied after a single dose of digitalis (table 3 , dog $B_{17}$ ). As can be seen the maximum decline in cardiac out-put came two days ( 50 hours) after the drug had been given whereas the cardiac out-put had returned to the normal level in six days (146 hours).

general concordance in the opinion that changes in cardiac out-put depend more on changes in the out-put per beat than on alteration in the cardiac rate. Our observations on digitalis are in entire support of this opinion. Digitalis produces variable effects on the pulse rate, but practically always reduces the out-put of the dog's heart, whether the pulse rate be decreased or augmented. Pulse rates are of little value in morphinized dogs because morphine is vagotonic in these 
animals. Hence the values for cardiac out-put per beat have not been included in the tables. In the seven experiments on trained unnarcotized animals (tables 3 and 4 ) the cardiac out-put per beat was decreased in four instances, the degree of decrease varying from 30 to 55 per cent. There was no change in out-put per beat in one

TABLE 4

Showing effects of digitalis on trained narcotized dogs with elevated metabolic rates and increased cardiac outputs

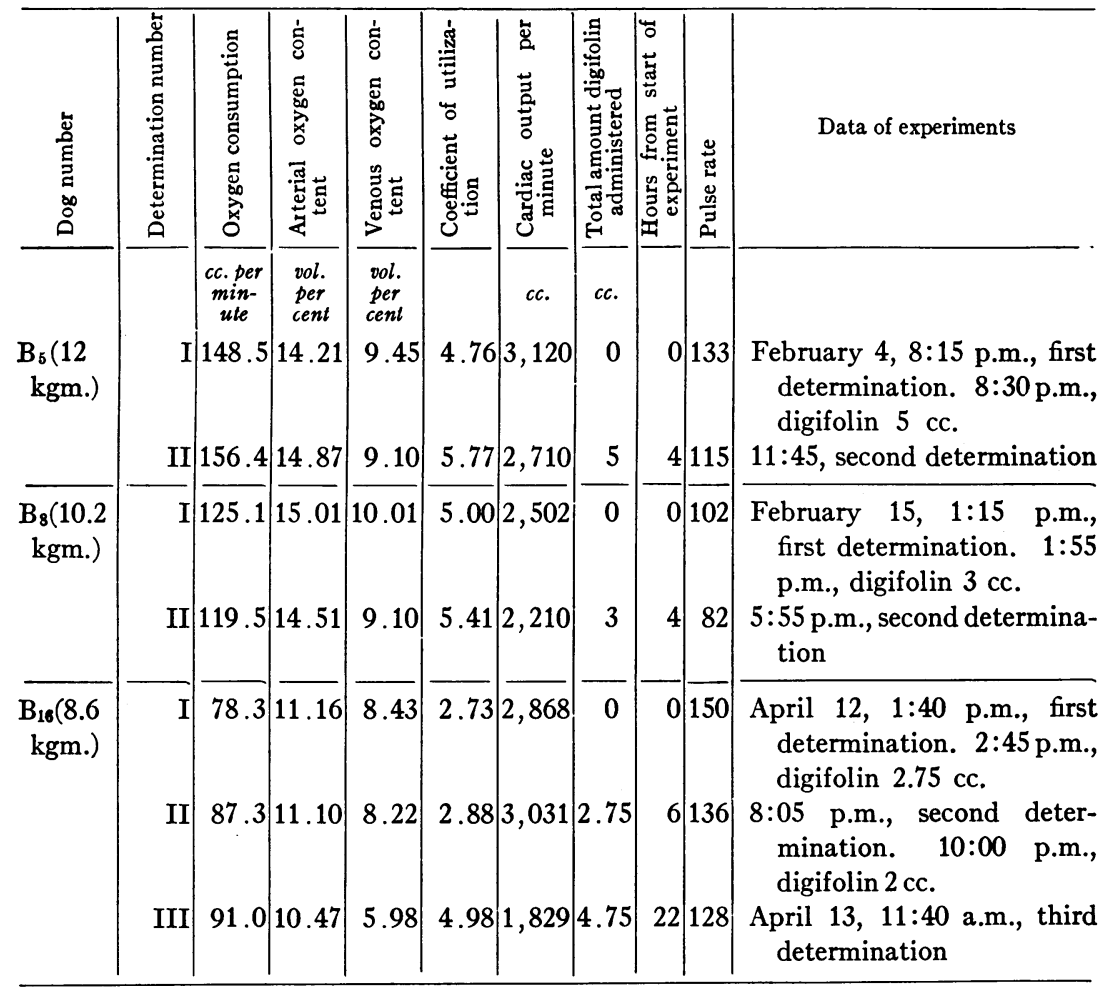

Note: The doses of digifolin were all "therapeutic," or less.

experiment while in two instances increases of 6 and 11 per cent were found.

The effect of digitalis on dogs with an increased cardiac out-put. Two of the animals recorded in table 4 had been fed thyroid gland. They had an increased metabolic rate $(+79$ per cent and +54 per cent $)$ and 
an increased catdiac out-put $(+115$ per cent and +69 per cent). The third animal had been subjected to excessive bleeding over a long period of time and also had an increased metabolic rate $(+58$

TABLE 5

Showing effects of digitalis in auricular fibrillation (morphinized dog)

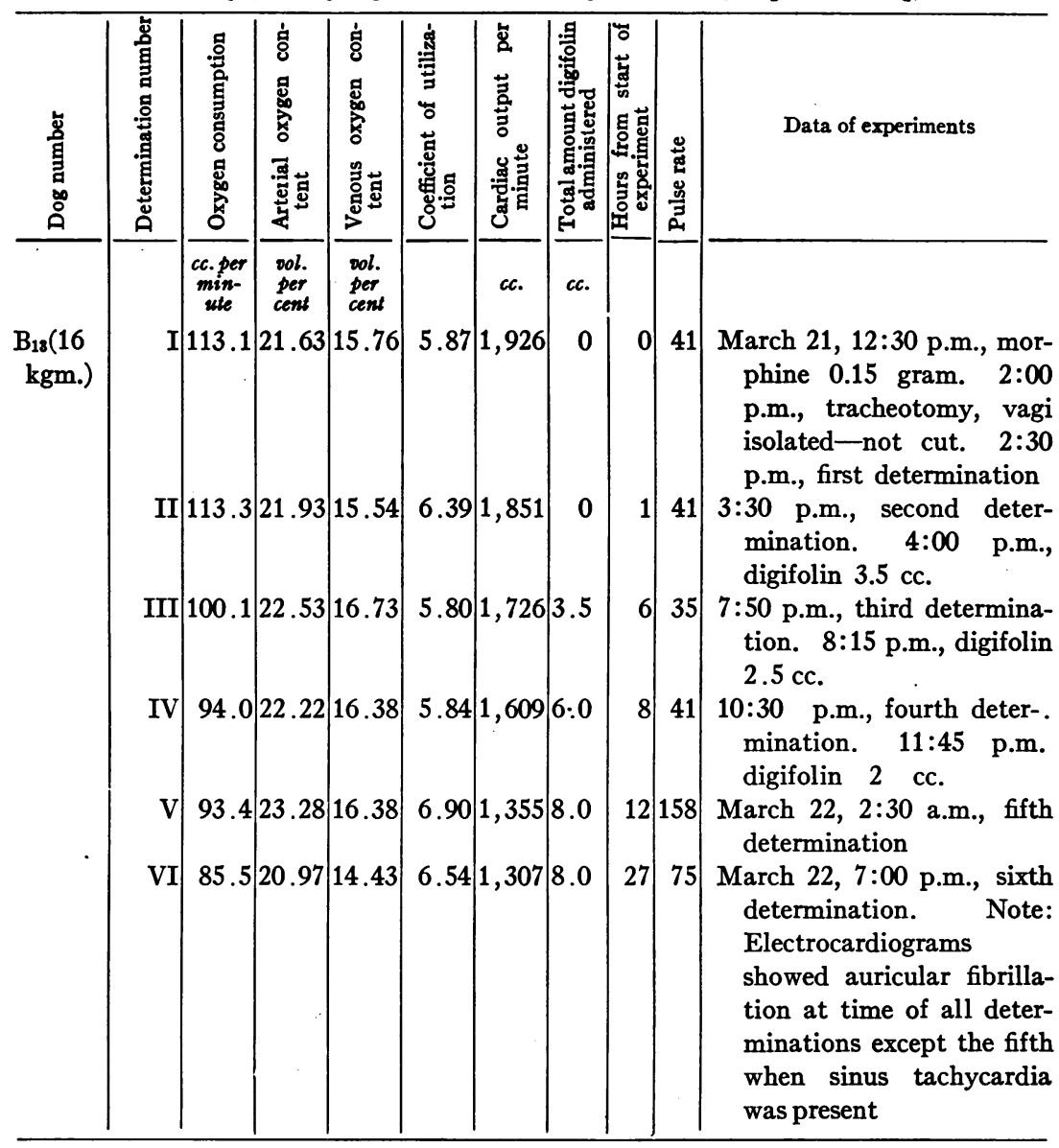

per cent) and increased cardiac out-put $(+237$ per cent). In the first two animals digitalis caused no significant change in oxygen consumption and a decrease of 13 and 12 per cent respectively in cardiac out-put. In the third animal the oxygen consumption was increased 
after the drug; the cardiac out-put at the end of 6 hours was increased by 6 per cent but at the end of 22 hours was decreased by 37 per cent. The average change in cardiac out-put for these four determinations was 14 per cent-somewhat less than the average figure for normal dogs receiving similar doses of the drug.

The effeci of digitalis in auricular fibrillation. One animal developed auricular fibrillation after manipulations of the vagi, but before these nerves were cut. The effect of digitalis in this animal (table 5) was similar to that obtained with similar doses of the drug in animals

TABLE 6

Showing effect of vagotomy or atropinization on cardiac output of previously digitalized dog

\begin{tabular}{|c|c|c|c|c|c|c|c|c|}
\hline Dog number & 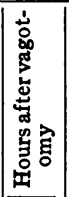 & 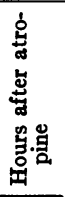 & 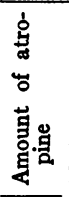 & 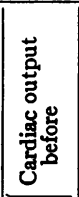 & 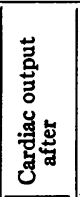 & 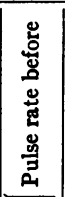 & 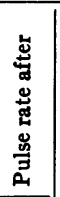 & Remarks \\
\hline$B_{14}(12$ kgm.) & & 0.5 & $\begin{array}{c}m g m . \\
1.5\end{array}$ & 1,879 & 2,042 & 72 & 214 & Trained unnarcotized dog \\
\hline$B_{15}(16 \quad$ kgm. $)$ & & 0.5 & 2.0 & 2,018 & 754 & 109 & 300 & Trained unnarcotized dog \\
\hline$B_{17}(16 \quad$ kgm. $)$ & & 0.75 & 1.25 & 2,000 & 1,841 & 120 & 176 & Trained unnarcotized dog \\
\hline$B_{18}(12 \quad \mathrm{kgm})$. & & 0.75 & 1.00 & 1,551 & 1,132 & 160 & 266 & Trained unnarcotized dog \\
\hline$B_{19}(10.1$ kgm. $)$ & 0.75 & & & 1,476 & 1,224 & 162 & 222 & $\begin{array}{l}\text { Dog narcotized with mor- } \\
\text { phine }\end{array}$ \\
\hline $\mathrm{B}_{13}(16.0 \mathrm{kgm})$. & 3.2 & & & 1,316 & 1,715 & 66 & 222 & $\begin{array}{l}\text { Dog narcotized with mor- } \\
\text { phine (auricular fibrilla- } \\
\text { tion present before vago- } \\
\text { tomy-sino-auricular } \\
\text { rhythm after vagotomy) }\end{array}$ \\
\hline
\end{tabular}

having a normal sino-auricular rhythm. The decrease in cardiac out-put eight hours after the "full therapeutic dose" was 28 per cent and after 22 hours amounted to 31 per cent. This was greater than the average decrease from comparable doses in the other dogs, but was less than the degree of change which was found in several instances. This experiment suggests that digitalis affects the fibrillating heart in the same manner as the normal heart, but possibly in greater degree. We draw no conclusions however from a single experiment.

The mechanism by which digitalis acts. on the cardiac output. In order to obtain some evidence on this point the vagi were cut or 
atropine was given several dogs after full therapeutic doses of digitalis. The results are shown in table 6 . The results were not conclusive. After vagotomy the cardiac out-put was increased in one experiment and decreased in another. After atropinization the. out-put was increased slightly in one experiment and diminished by varying degrees in three instances. In none of the experiments did the cardiac out-put rise to the original level before digitalization. These results lead us to believe that digitalis affects the contraction of the heart by direct myocardial action, but we do not regard this point as definitely established.

TABLE 7

The relation of changes in cardiac output to the dose of digitalis

\begin{tabular}{l|c|c|c|c}
\hline & $\begin{array}{c}\text { I } \\
\text { Less than } \\
\text { one-half of } \\
\text { therapeutic dose } \\
\text { (less than 0.25 } \\
\text { c. per kilogram) }\end{array}$ & $\begin{array}{c}\text { II } \\
\text { One-half to } \\
\text { full therapeutic } \\
\text { dose (0.25 to } \\
0.5 \text { cc. } \\
\text { per kilogram) }\end{array}$ & $\begin{array}{c}\text { III } \\
\text { One to one and } \\
\text { one-half thera- } \\
\text { peutic dose (0.5 } \\
\text { to 0.75 cc. } \\
\text { per kilogram) }\end{array}$ & $\begin{array}{c}\text { IV } \\
\text { More than one- } \\
\text { half therapeutic } \\
\text { doses (more } \\
\text { than 0.75 cc. } \\
\text { per kilogram) }\end{array}$ \\
\hline Number of determinations..... & 6 & 23 & 7 & 9 \\
Highest cardiac output, per cent. & +6 & +32 & -23 & -32 \\
Lowest cardiac output, per cent. & -45 & -56 & -33 & -67 \\
Average cardiac output, per cent. & -18 & -23.3 & -27.7 & -46.3 \\
\hline
\end{tabular}

\section{Electrocardiograms}

Frequent electrocardiograms were made during the course of each experiment. The purpose in mind was two-fold: $(a)$ to control the dosage of digifolin, by rendering certain the fact that doses considered therapeutic in quantity produced no changes in cardiac mechanism that might be interpreted as being due to serious myocardial damage, and which, in themselves, might conceivably alter the cardiac out-put; (b) to correlate, if possible, typical digitalis electrocardiographic effects with changes in the cardiac out-put. Lead II was used throughout.

A brief description of electrocardiographic results follows.

I. A. Electrocardiographic changes observed in dogs receiving morphine followed by digifolin in quantilies considered to be equivalent to or less than the therapeutic dose. Four dogs had records made before the administration of morphine sulphate. The average amount of the drug used was $14 \mathrm{mgm}$. per kilogram. After an average of 3 hours marked 
reductions in heart rate were obtained in each case, the average decrease being 56 per cent. Three of the four dogs showed increases in the P-R interval varying from 0.01 to 0.02 second. In one instance there was no change in the P-R interval. Three of the four dogs showed definite increases in the height of the $T$ wave; in one instance there was no change. In three experiments without control records prior to the administration of morphine, in quantities averaging 11 $\mathrm{mgm}$. per kilogram, the average rate per minute after an average of $1 \frac{2}{3}$ hours was 56. The P-R intervals were $0.14,0.12$ and 0.14 second. The $T$ wave in each case was upright and varied from $1 \mathrm{~mm}$. to $7.5 \mathrm{~mm}$.

Following the administration of digifolin there was an increase in rate in every case with the exception of one, in which there was practically no change. The maximum increases during the course of the respective experiments were $12,16,145,180,346$ and 502 per cent. In the case showing the 180 per cent increase in rate there was no disturbance in the cardiac mechanism other than a sinoauricular tachycardia. The 346 per cent increase in rate was due to the development of an auricular tachycardia of a rate of 214 per minute. The 145 per cent increase in rate in another dog was due to the development of an abnormal rhythm, ventricular tachycardia alternating with normal sino-auricular rhythm. The 502 per cent increase in rate was due to the development of an auricular tachycardia, rate 250 per minute. The important points noted in this connection were: $(a)$ the fact that characteristic diminution, in cardiac out-put were found some time prior to the development of the fast rates, when there had been no significant increase in cardiac rate or disturbance in cardiac mechanism, and $(b)$ the fact that the development of the rapid rates seemed, per se, to have no effect on the cardiac out-put. The only exception to be made is the case with the 145 per cent increase in rate, where the characteristic diminution in cardiac out-put was accompanied by the abnormal rhythm mentioned.

There was no constant variation in the P-R interval or the height of the $T$ wave, and therefore no correlation between these changes, the amount of digifolin used and the cardiac out-put could be made. However, it was interesting to note that in every case with one exception digifolin given to the morphinized dogs produced a definite decrease in the P-R interval, irrespective of the cardiac rate. 
B. Electrocardiographic changes following digifolin in amounts above the therapeutic dose in morphinized dogs. There were four dogs in this group, receiving digifolin in amounts varying from 0.5 to 2.1 cc. per kilogram, the drug being administered in doses of 1 to $3 \mathrm{cc}$. at intervals over periods of time varying from 20 to 27 hours. In every instance there was a marked increase in rate, due in three cases to the development of auricular tachycardia, with rates varying from 186 to 240 per minute, and in the remaining case to sinus tachycardia with a rate of 139 per minute. There was no constant variation in the P-R interval or in the height or sign of the $\mathrm{T}$ wave.

In summary, with "therapeutic" amounts of digifolin, three of seven dogs suffered significant changes in cardiac mechanism, two developing auricular tachycardias and the third an abnormal rhythm consisting of ventricular tachycardia alternating with normal sino-auricular rhythm. Four dogs were given doses greater than the therapeutic amount. Three developed auricular tachycardia; the remaining dog exhibited no significant change in cardiac mechanism. In every instance with one exception, characteristic diminution in cardiac out-put was obtained prior to the development of the abnormal rhythms. The P-R interval varied in either direction, and no constant changes in the $T$ wave to indicate digitalis effect were noted.

II. Electrocardiographic changes in trained, unnarcotized dogs, following digifolin in therapeutic and sub-therapeutic doses. Of the seven dogs studied, four had decreases in rate following digifolin, varying from 10 to 25 per cent. The P-R interval in two of the four increased by 0.01 and 0.02 second respectively, while in the remaining two there was a decrease of 0.03 and 0.01 second. The $T$ wave underwent inversion in only one of the four and this occurred simultaneously with the characteristic diminution in cardiac out-put.

The ventricular rate in three animals was increased, 25, 38 and 66 per cent respectively. The P-R interval in the first of the three dogs was increased by 0.01 second and in the second it was decreased by 0.03 second. The first dog showed rather frequent ventricular premature contractions, at the time the characteristic drop in cardiac out-put occurred. The 66 per cent increase in rate in the third animal was due to the development of a sino-auricular tachycardia, rate 250 . This dog, $\mathbf{B}_{18}$, three hours after two-thirds of a therapeutic dose of 
digifolin, showed a diminution of 11.2 per cent in cardiac out-put' The fast rhythm appeared 13 hours after the drug and was accompanied by a further drop of 14 per cent in cardiac out-put. However, 21 hours later, with a rate of 150 and normal mechanism, the cardiac out-put was practically the same as that at the time of the rapid rhythm.

\section{NECROPSY FINDINGS}

In two experiments the pericardium was found to contain blood. These experiments were discarded and are not included in our tables. The pericardial sacs of the remaining animals contained less than 5 cc. or no blood. In those animals which were given toxic doses of digitalis and allowed to die from the effect of the drug, the heart was found firmly contracted and the heart chambers were free of blood. This phenomenon of systolic standstill is well recognized as a sequel of digitalis poisoning. The hearts of the other animals-those sacrificed with ether after receiving sub-lethal doses of digifolin-appeared to contain less blood than the hearts of normal dogs and the ventricular walls were firm. We gained the impression that these hearts were somewhat smaller then the hearts of dogs which had received no digitalis, but of this we have no proof. It was noted, however, in many of the experiments, that ventricular punctures which could be carried out with ease in the control observations, became increasingly difficult as digitalis was administered, and this was attributed to a diminishing size of the ventricular cavities. We frequently found it necessary to use a long needle to enter the ventricle of the digitalized dog whereas a short needle had sufficed for the control puncture.

$\mathrm{X}$-ray studies were not made of the heart size. These would have been desirable. In their absence it is felt that the above observations, taken together with the findings of Strong and Gordon (13) (diminished size of the rabbit's heart after strophanthin), and Levy (14) (diminished size of the heart of patients with pneumonia after digitalis) indicate that digitalis both in the therapeutic and toxic doses diminishes the volume of the heart. We agree with Schmoll (7) that the essential action of digitalis is concerned with an increased tonicity of the heart. The significance of this conception is discussed below. 
DISCUSSION

In view of the fact that animals used in our experiments were entirely intact and had not been subjected to operative procedures, in view of the fact that more than one third of the experiments were carried out on trained unnarcotized healthy dogs, and in view of the uniform results obtained, we feel that there can no longer be any question as to the action of digitalis on the output of the heart of the normal dog. Digitalis diminishes the out-put of the normal dog's heart.

The drug may or may not have the same effect on the diseased heart of man. In the observations quoted above by Eppinger, von Papp and Schwarz (18) a decrease of about 25 per cent in the cardiac out-put occurred in a patient with valvular heart disease after a full therapeutic dose of digitalis had been given. In the other case which they studied after digitalis had been given, a patient with aortic insuffciency, the cardiac out-put was about 16 per cent less on the third day of digitalis administration than on the first day, but the relation of the action of the drug to the decrease in the cardiac out-put is not definite. On the basis of these observations one is scarcely justified in stating that the drug has the same effect on patients with heart disease as it has on normal dogs. However most drugs affect man in the same manner as the dog; most drugs act on diseased indviduals and normal individuals in similar manner. Consequently we believe that it is altogether likely that digitalis diminishes the out-put of the heart in man. It is difficult to reconcile this view with the findings of Cohn and Stewart (15) who noted an increase in the ventricular excursion as judged by moving orthodiagrams after digitalization. Changes in the size of the heart shadow do not necessarily postulate similar changes in heart volume and these observers, recognizng this fact, interpreted their results as meaning that digitalis affects the contractility of the heart in man and did not claim to have demonstrated an increase in cardiac out-put.

The following discussion is based on the assumption-which is only an assumption, though seemingly a likely one-that digitalis has the same effect on the human heart as on the dog's heart. If this is granted certain points seem worthy of emphasis. 


\section{The sedative action of digitalis}

The work of the heart depends on numerous factors of which the most important are, (a) the cardiac out-put, (b) the blood pressure, (c) the blood viscosity, $(d)$ the elasticity of the blood vessels and $(e)$ the total volume of circulating blood. In our experiments the last three factors may be considered as constant. Blood pressure was not measured but it is generally recognized that digitalis in therapeutic doses has no significant effect on blood pressure either in man or in the experimental animal.

Since digitalis has no significant effect on the other factors entering into the work of the heart and since it diminished the amount of blood pumped by the heart, the drug may be asserted to diminish the work of the heart and in this sense is to be regarded as a cardiac sedative. It is probable that this sedative action is more marked in diseased than in normal hearts as will be pointed out later.

The conception of digitalis as a cardiac sedative is contrary to current opinion. The drug has been generally considered by clinicians as a "cardiac tonic" despite the conflicting experimental evidence upon which this idea is based.

From the point of view of the sedative action, digitalis may be considered as affecting the circulation in the same way as morphine affects the respiration. The value of morphine in the various forms of severe dyspnea of respiratory origin is unquestioned. Morphine is known to be a respiratory sedative, and in view of our experiments we believe that digitalis acts on the circulation in a similar manner-by resting an over-strained mechanism. The evidence that digitalis decreases the work of the dog's heart is conclusive and by analogy to morphine the evidence that the drug decreases the work of the diseased human heart becomes very suggestive.

In pneumonia the respiratory minute volume is increased. Harrison and Blalock (25) have recently shown that the circulatory minute volume is also increased in dogs with this disease, and Leegaard (26) found the same result in rabbits. For many years the value of morphine in pneumonia has been considered as questionable, because the "depressing" effect on respiration was feared. This fear has been largely overcome and morphine has come in the last few years to 
occupy an important place in the treatment of pneumonia (27) (28) (29). Similar uncertainity has existed concerning the value of digitalis in pneumonia (30), although Cohn and Jamieson (31) showed that digitalis has the same effect in patients with pneumonia as in patients without pneumonia, and Levy (14) demonstrated a decrease in the size of the heart after digitalization in pneumonia. The explanation for the lack of favorable results in pneumonia from digitalis may lie in the fact that the drug is usually not given at all or is given in small doses for the first few days of the disease and then "pushed" when "signs of circulatory failure" develop. In view of the conception of digitalis as a cardiac sedative it would seem that digitalis has been incorrectly used in pneumonia. If given at all the drug should be given early in the disease and in full therapeutic doses, for it is early in the disease that the cardiac out-put is probably increased-if the human heart reacts to pneumonia in the same manner as the heart of the dog and rabbit-and "circulatory failure" in pneumonia is probably at least partially dependent on pre-existing strain from increased out-put over a period of several days. We believe that digitalis is contraindicated in pneumonia when outstanding evidence of "circulatory failure" is present, as it is likely then under this condition the out-put of the heart is already much diminished. Digitalis should be used to prevent and not to combat "circulatory failure" in pneumonia.

There is therefore rational experimental evidence to believe that digitalis given early and freely may be of considerable value in pneumonia, whereas its value late in the disease is questionable, and quite possibly the drug is harmful under these conditions.

The tonic action of digitalis has been considered for years as the essential feature of the action of the drug. This is true in one sensebut in a different sense from the usual idea of "tonic" action. Digitalis has been generally considered to increase the contractility and consequently the out-put of the heart. The drug has just the opposite effect in the dog and probably in man. However, there is evidence to indicate that digitalis in therapeutic doses increases the tonicity of the heart muscle. Strong and Gordon (13) found a diminution in the size of the heart shadow in normal rabbits and rabbits with experimental myocarditis after administration of strophanthin. Levy (14) 
reported a similar effect from digitalis in patients with pneumonia. Systolic "stand-still" is the generally recognized effect of lethal doses and we have referred above to our difficulty in puncturing the ventricles after digitalization.

Schmoll (7) in 1911 claimed that the essential action of digitalis was the effect on tonicity. In the light of our observations we agree with Schmoll and believe that digitalis acts on the heart by increasing the tonus of the muscle, the diminished contractility being a secondary effect and being dependent on a diminished diastolic relaxation. In this sense digitalis is a "cardiac tonic." The term is obviously misleading, as it may denote either augmented contractility or augmented tonicity and these are functionally opposite effects.

\section{The action of digitalis in heart disease}

It has been almost universally assumed that such symptoms as dyspnea and orthopnea and such signs as cyanosis, edema and engorgement of the liver and lungs, are dependent on diminished cardiac out-put and the object of treatment has been believed to be an increase in out-put. Considerable evidence has been accumulated against this view. Thus the ideas of fifty years ago as to the value of exercise have been completely abandoned, as Pratt (32) has pointed out. Henderson and Haggard (33) have recently shown that the out-put of the heart is less when a person is sitting than when lying down. Field and Bock (34) have confirmed this finding and have indicated the significance of this observation from the viewpoint of the interpretation of orthopnea. The latter authors regard orthopnea as a protective mechanism, the patient being more comfortable in the sitting position, because the cardiac out-put is diminished. Everyone who has watched many cardiac patients has noted that some of them, when in great distress, hang their feet over the side of the bed, and this, as the above investigators have shown diminishes the out-put still more. This leads us to the conclusion that those measures which diminish the out-put of the heart are beneficial in cardiac insufficiency and this conclusion constitutes one of the strongest links of evidence that digitalis diminishes the out-put of the insufficient human heart, as well as the out-put of the normal dog's heart.

Furthermore there is reason to believe that the cardiac out-put is 
not diminished in all cases of cardiac insufficiency. Eppinger, Kisch and Schwarz (35) report observations on the cardiac out-put of a patient with mitral disease, who had a minute out put of 5.15 liters when "fully compensated" and a year later when decompensated" the minute out-put was 10.13 liters. Eppinger, von Papp and Schwarz (18) found a great increase in minute out-put in patients with acute pulmonary edema (cardiac asthma). The same investigators found a normal or low coefficient of utilization of oxygen in a large percentage of their cases of mitral and aortic disease with "decompensation," indicating that the cardiac out-put was probably not diminished. These investigators are inclined to stress the importance of the peripheral circulation in the production of cardiac insufficiency and believe that the essential factor in cardiac failure is a lack of functional balance between the two ventricles rather than diminished cardiac out-put. This conception explains why some patients have congestion of the lungs without congestion of the systemic circulation and why other patients have edema of the extremities and engorgement of the liver without râles in the lungs-facts which are difficult of explanation on the basis of an assumption that diminished cardiac out-put and consequent general slowing of the blood stream are the essential factors in producing the signs of decompensation. These two theories of the mechanism of cardiac insufficiency are almost diametrically opposed. The one theory states that the important feature is the "level" (or amount) of cardiac out-put; the other asserts that it is the "balance" or coördination of the various circulatory functions that is the essential factor in maintaining circulatory efficiency.

Our findings in regard to digitalis are particularly compatible with the latter conception. If "decompensation" is primarily due to the fact that one ventricle is unable to keep pace with the other, then anything which diminishes the total cardiac out-put should tend to reëstablish the balance at a lower level. This is what digitalis apparently does-protects the weaker ventricle from overstrain by the stronger.

In cardiac decompensation with relative mitral or tricuspid insuffciency digitalis may cause increased tone of the auriculo-ventricular rings. It is possible that the drug lessens regurgitation by this means, and if so the efficiency of the heart is increased, while the work is 
decreased. This conception may explain the well recognized fact that the digitalis is more beneficial in mitral incompetence than in aortic incompetence. Relative aortic insufficiency is very rare and one would expect more benefit in those cases in which the mechanical defect is diminished.

Our findings have led us to believe that digitalis has two general indications. (a) To combat cardiac insufficiency and (b) to prevent cardiac insufficiency. The first of these indications is too well recognized to require further comment, but the second merits some discussion.

There are certain conditions in which there is evidence that the cardiac work is increased. Pneumonia has already been mentioned. Blalock and Harrison (36) have observed an increased cardiac out-put in chronic anemia in dogs, after successive bleedings. Robinson and Burwell (37) have found a great increase in cardiac out-put in a patient with hyperthyroidism. Davies, Meakins and Sand (38) report several observations of increased out-put in patients with this disease. Odaira (39), working with rabbits, and Blalock and Harrison (40) working with dogs found increased cardiac out-puts after feeding thyroid substance. Blalock, Harrison and Wilson (41) found increased cardiac out-put in experimental partial respiratory obstruction, whereas Harrison, Wilson and Blalock (25) found increased cardiac out-put in experimental acidosis. Harrison and Blalock (42) have recently observed a great increase in cardiac out-put in experimental anoxemia. Blalock (43) has noted increased cardiac out-put in dogs under ether anesthesia. Harrison, Dock and Holman (44) found increased cardiac out-put in experimental arterio-venous fistulae. There are possibly many other conditions, yet to be investigated, in which the out-put of the heart and consequently the strain on the heart, are increased. In many or all of these conditions the increased cardiac out-put is a compensatory mechanism, which may in itself be a source of danger by overstraining the heart to the point of failure or possibly by producing a lack of circulatory balance. We have found that digitalis decreases the out-put of the "hyperactive" hearts of thyrotoxic and anemic dogs (table 4). There is therefore a rational experimental basis for believing that this drug may be of value in preventing cardiac failure from overstrain in these conditions. If 
given to patients suffering from any of the above conditions digitalis should be given early, before evidence of circulatory failure develops. (See discussion on pneumonia above.) The experimental evidence is sufficient to warrant a thorough trial of digitalis in patients suffering from the above conditions: the final answer as to whether digitalis is valuable in such instances must rest upon carefully controlled clinical observations of many well studied cases.

\section{Contraindications for digitalis}

The drug is widely used in all forms of acute and chronic circulatory failure from all causes, and much uncertainity exists as to its value in many groups of patients. Our results lead us to believe that digitalis is contraindicated whenever evidence of diminished cardiac out-put exists without simultaneous evidence of lack of ventricular balance. In the absence of extensive studies on cardiac out-put in man these criteria are difficult to apply. We can only interpret such evidence as is available and hold our interpretation open to change in the light of newer advances. To be more specific: in the absence of local causes, we may consider congestion of the liver, lungs or extremities, ascites and hydrothorax as evidences of lack of ventricular balance and as indications for digitalis regardless of whether cardiac out-put is believed to be decreased, increased or normal. When none of these signs are present, a feeble, rapid, regular pulse associated with faint heart sounds, with or without dyspnea, orthopnea and cyanosis may be regarded as evidence of diminished cardiac out-put and as a contraindication to digitalis. Such conditions are found in surgical or traumatic shock, after prolonged anesthesia-particularly in elderly persons, in acute peritonitis, in the terminal stages of most acute infectious diseases, including lobar pneumonia, and in patients moribund from any cause. Digitalis is widely used in such cases because of its supposed "tonic" action on the heart. The evidence presented in this paper suggests that when so used the drug may be harmful. As a matter of fact when digitalis is given to these patients it is often administered intramuscularly as digifolin in doses of one to three cubic centimeters a day, and such doses probably have no effect at all. If the drug were administered in full amount in such cases we should probably see harmful effects occasionally. As it is one does not usually observe any effect from digitalis in these patients. 


\section{SUMMARY}

The cardiac out-puts of morphinized dogs and trained unnarcotized dogs have been studied by the Fick method before and after the intramuscular administration of digifolin. The following results have been obtained:

1. The calculated "full therapeutic dose" of the drug caused an average decrease of approximately 25 per cent in the cardiac output per minute.

2. Smaller doses than the above caused a definite but smaller decrease and larger doses a greater decrease in the cardiac out-put per minute.

3. Although individual dogs showed marked variations in the quantitative effect of the drug on cardiac out-put, the qualitative effect (diminution in minute out-put) was similar in all the dogs studied.

4. The maximum effect of a single dose became manifest in about six hours from the time of administration, and lasted for about fortyeight hours. The cardiac out-put then gradually increased, reaching the normal level in approximately six days.

5. One dog with auricular fibrillation responded to digifolin by a decrease in cardiac out-put, slightly but not significantly greater than the decrease found in the animals with normal mechanism.

6. Three dogs with increased cardiac out-put showed an average decrease of 14 per cent after digifolin.

7. The effects of vagotomy and atropinization of previously digitalized dogs were variable. The cardiac out-put did not return to the normal level in any instance.

8. Although the changes in minute cardiac out-put were uniform, the changes in pulse rate, in oxygen consumption, in out-put per beat, and in the electrocardiograms were variable.

9. Evidence has been presented to show that the results obtained after digitalization are probably primarily dependent on an increased tonicity of the heart muscle.

In order to consider the clinical application of the above findings it has been necessary to assume without definite proof that digitalis affects the diseased human heart in the same manner as it affects the normal dog's heart. Considerable evidence for this hypothesis 
has been presented. On the basis of this assumption the following points are emphasized.

1. Digitalis is a cardiac sedative in one sense-it diminishes cardiac out-put and hence diminishes cardiac work. The effect of digitalis on the circulation is considered as somewhat analagous to the effect of morphine on the respiration.

2. Digitalis is a cardiac tonic in another sense-it increases tonicity and diminishes dilatation.

3. The action of digitalis furnishes evidence for the idea that a failure in ventricular balance is an important factor, if not the most important factor, in the production of the symptoms of cardiac insufficiency. This is opposed to the conception of cardiac failure as being dependent primarily on a general diminution of the out-put of the heart.

4. The beneficial action of digitalis in cardiac insufficiency with normal rhythm is to be attributed to two factors: $(a)$ the effect on contractility-diminished work, and (b) the effect on tonicity-increased cardiac efficiency from decreased regurgitation and diminished dilatation. It is believed that digitalis has a more striking effect on the work of the decompensated heart than on the work of the normal heart.

5. No definite correlation has been found to exist between changes in the cardiac mechanism as revealed by electrocardiograms and changes in cardiac out-put.

6. The indications for digitalis are believed to be:

$a$. To combat cardiac insufficiency. This is in agreement with general clinical experience.

$b$. To prevent cardiac insufficiency in patients in whom the heart is subjected to the strain of prolonged, increased work. Examples are: (1) mechanical defects, as valve lesions; (2) increased systemic or pulmonary blood pressure-as hypertension or asthmatic bronchitis; (3) prolonged increased cardiac out-put-as hyperthyroidism, pneumonia, anemia, anoxemia, etc. The clinical evidence for the value of digitalis in these cases is not conclusive.

9. The contraindications for digitalis may be summarized as those conditions in which the clinical picture indicates acute circulatory failure or shock, without evidence of visceral or peripheral congestion. 
When the cardiac out-put is believed to be materially decreased and simultaneous evidence for lack of ventricular balance does not exist, digitalis, if given in effective doses, may be expected to have a harmful action.

We are indebted to Dr. C. Sidney Burwell for helpful suggestions. It is a pleasure to express our appreciation to him and to Dr. G. Canby Robinson, whose interest, advice, and kindly criticism have made this work possible.

\section{BIBLIOGRAPHY}

1. Robinson, G. Canby: The Therapeutic Use of Digitalis. Baltimore, 1923.

2. Cushny, A. R.: The Action and Uses in Medicine of Digitalis and its Allies. London, 1925.

3. Gottlieb, R., and Magnus R.: Arch. f. Exp. Path. u. Pharm., 1903, li, 30. Digitalis und Herzarbeit.

4. Magnus, R., and Sowton, S. C. M.: Arch. f. Exp. Path. u. Pharm., 1910, lxiii, 255. Zur Elementarwirkung der Digitaliskörper.

5. Cushny, A. R.: (2), p. 118.

6. Cushny, A. R.: (2), p. 113.

7. Schmoll, Emile: Amer. Jour. Med. Sc., 1911, cxli, 35. The Tonic Use of Digitalis.

8. Gottlieb, R.: Quoted by Robinson (1), p. 43.

9. Schmiedeberg: Quioted by Robinson (1), p. 43.

10. Cushny: (2), p. 117.

11. Cohn, A. E.: Jour. Amer. Med. Assoc., 1915, lxv, 1527. Clinical and Electrocardiographic Studies on the Action of Digitalis.

12. Cohn, A. E., and Levy, R. L.: Proc. Soc. Exp. Biol. and Med., 1920, xvii, 160. The Effect of Therapeutic Doses of Digitalis on the Contraction of Heart Muscle.

13. Strong, G. F., and Gordon, Burgess: Arch. Int. Med., 1923, xxxii, 510. Studies on the Rabbit's Heart. I. Effect of Strophanthin on the Size of the Normal and of the Abnormal Heart.

14. Levy, R. L.: Arch. Int. Med., 1923, xxxii, 359. Size of the Heart in Pneumonia. A Teleroentgenographic Study, with Observations on the Effect of Digitalis Therapy.

15. Cohn, A. E., and Stewart, H. J.: Jour. Clin. Invest., 1924, i, 97. Evidence that Digitalis Influences Contraction of the Heart in Man.

16. Vagt: Quoted by Cushny (2), p. 159.

17. Kauffman, Rudolph: Zeitsch. f. Exp. Path. u. Ther., 1913, xii, 165. Ueber den Einfluss des Schmerzes u. der Digitalis auf die Herzarbeit des normalen Menschen. 
18. Eppinger, Hans, von Papp, L., and Schwarz, H.: Utber das Asthma Cardiale. Berlin, 1924; p. 191.

19. Van Slyke, D. D., and Neill, J. M.: Jour. Biol. Chem., 1924, lxi, 523. The Determination of Gases in Blood and Other Solutions by Vacuum Extraction and Manometric Measurement.

20. Pardee, H. E. B.: Jour. Amer. Med. Assoc., 1925, lxxxv, 1359. Hypodermic Digitalis Preparations.

21. Barcroft, S.: Jour. Physiol., 1925, lx, 443. A Contribution to the Physiology of the Spleen.

22. Marshall, E. K., Jr.: Amer. Jour. Physiol., 1925, lxxii, 192. Cardiac Output.

23. Harrison, Tinsley, R., Wilson, Charles P., and Blalock, Alfred: Jour. Clin. Invest., 1925, R, 547. The Effects of Changes in Hydrogen Ion Concentration on the Blood Flow of Morphinized Dogs.

24. Henderson, Yandell: Lancet, 1925, ii, 1317. Efficiency of Heart and Its Measurement.

25. Harrison, Tinsley R., and Blalock, Alfred: Jour. Clin. Invest., 1926, ii, 435. Cardiac Out-put in Pneumonia in the Dog.

26. Leegaard, T.: Skand. Arch. f. Physiol., 1925, xlvi, 323. The Output of the Heart in Experimental Pneumonia.

27. Cole, Rufus: Nelson Loose Leaf Living Medicine, vol. i, p. 258. Treatment of Acute Lobar Pneumonia.

28. Lord, Frederick T.: Ibid., p. 305. Bronchopneumonia.

29. Austrian, Charles R.: Tice's Practice of Medicine, iii, 62. New York.

30. Irons, Ernest E.: Oxford System of Medicine, iv, 855. New York. Acute Lobar Pneumonia.

31. Cohn, A. E., and Jamieson, R. A.: Jour. Exp. Med., 1917, xxv, 65. The Action of Digitalis in Pneumonia.

32. Pratt, Joseph H.: South. Med. Jour., 1920, xiii, 481. Rest and Exercise in the Treatment of Heart Disease.

33. Henderson, Yandell, and Haggard, H. W.: Amer. Jour. Physiol., 1925, lxxii, 193. The Circulation and Its Measurement.

34. Field, H. Jr., and Bock, A. V.: Jour. Clin. Invest., 1925, ii, 67. Orthopnea and the Effect of Posture upon the Rate of Blood Flow.

35. Eppinger, Hans, Kisch, Franz, and Schwarz, Heinrich: Klin. Woch., 1925, iv, 1101. Arbeit und Kreislauf.

36. Blalock, Alfred, and Harrison, Tinsley R.: Unpublished Observations on the Cardiac Output in Anaemia.

37. Robinson, G. Canby, and Burwell, C. Sidney: Personal communication.

38. Davies, J. W., Meakins, J., and Sands, J.: Heart, 1924, xi, 299. The Influence of Circulatory Disturbances on the Gaseous Exchange of the Blood. V. The Blood Gases and Circulation Rate in Hyperthyroidism. 
39. Odaira, T.: Tohoku Jour. Exp. Med., 1925, vi, 325. Studien über Gasstoffwechsel und minutenvolum. I. Die Beziehung des Gasstoffwechsels und minutenvolums zur inneren Sekretion.

40. Blalock, Alfred, and Harrison Tinsley R.: Unpublished Observations on the Cardiac Output in Experimental Hyperthyroidism.

41. Blalock, Alfred, Harrison, Tinsley R., and Wilson, Charles P.: Arch. of Surg., 1926, xiii, 81. The Effect of Partial Tracheal Obstruction on the Circulation and Respiration of Morphinized Dogs.

42. Harrison, Tinsley R., and Blalock, Alfred: Unpublished Observations on the Effect of Anoxemia on Cardiac Output.

43. Blalock, Alfred: Personal communication.

44. Harrison, Tinsley R., Dock, William, and Holman, Emile: Heart, 1924, xi, 337. Experimental Studies on Arterio-Venous Fistulae; Cardiac Output. 